\title{
Primary Episcleral Melanoma Consistent with Uveal Melanoma Mutations Treated by Excision and Gamma Knife Stereotactic Radiosurgery
}

\author{
Spencer T. Langevin ${ }^{\mathrm{a}}$ Eileen Chang ${ }^{\mathrm{b}}$ Tony J.C. Wang ${ }^{\mathrm{c}}$ Israel Deutsch ${ }^{\mathrm{c}}$ \\ Marc Otten ${ }^{d}$ Brian P. Marr ${ }^{a}$ \\ a Department of Ophthalmology, Edward S. Harkness Eye Institute, Columbia University Irving Medical Center, \\ New York, NY, USA; ${ }^{b}$ Department of Ophthalmology, Nassau University Medical Center, East Meadow, NY, USA; \\ ${ }^{\mathrm{C}}$ Department of Radiation Oncology, Columbia University Irving Medical Center, New York, NY, USA; ${ }^{\mathrm{d}}$ Department \\ of Neurosurgery, Columbia University Irving Medical Center, New York, NY, USA
}

\section{Established Facts}

- Ocular melanocytosis is traditionally associated with increased risk of uveal melanoma.

- Primary episcleral melanoma has been reported in the literature, however, in very rare cases.

- Primary episcleral melanoma has been treated by surgical excision in previous cases.

- Long-term survival is unknown.

\section{Novel Insights}

- In our case, the largest episcleral melanoma was excised.

- The origin of episcleral melanoma was determined to be uveal given both GNA-11 mutation and GEP testing in this case which was never performed before.

- Gamma Knife radiotherapy was administered to the surgical bed and surrounding orbit for the first time to treat any residual disease.

\section{Keywords}

Melanoma - Episcleral melanoma - Uveal melanoma · Gene expression profiling · Gamma Knife · Stereotactic radiotherapy

\section{Abstract \\ Ocular melanocytosis has traditionally been associated with increased risk of developing uveal melanoma; however,}

rarely primary episcleral melanoma has been reported in the literature. Herein, we present the third case of primary episcleral melanoma treated by complete excision and cryotherapy. In contrast to previous cases, we obtained molecular genetic testing which revealed a GNA-11 mutation, and gene expression profiling resulted in a Class 2 PRAME positive tumor diagnosis. These two tests which have never been performed on previous cases, support lineage similar to uveal melanoma. In addition, we are the first case to report treat-

\section{KARGER}

(C) 2019 S. Karger AG, Basel

E-Mail karger@karger.com

www.karger.com/oop
Brian P. Marr

Edward S. Harkness Eye Institute

Columbia University Irving Medical Center

635 W 165th Street, New York, NY 10032 (USA)

E-Mailbpm2133@cumc.columbia.edu 
ment of the surgical bed and surrounding orbital tissue with Gamma Knife stereotactic radiotherapy to both treat residual tissue and decrease risk of recurrence.

(c) 2019 S. Karger AG, Basel

\section{Introduction}

Melanoma is a rare tumor from malignant transformation of melanocytes located throughout various tissues of the body [1]. In the eye, this includes uvea, conjunctiva, eyelid, periocular skin, and orbit. The uveal tract is the most common anatomic location of ocular melanoma [2]. Based on the National Cancer Data Base (NCDB) with data collected from 1985 to $1994,85 \%$ of ocular melanomas were uveal melanomas [3]. Further breakdown of uveal melanomas based on anatomy of the uveal tract include $90 \%$ choroid, $6 \%$ ciliary body, and $4 \%$ iris in a study of 7,256 cases [4]. Uveal melanoma is found most commonly in Caucasians with approximately $98 \%$ of cases occurring in the white population $[1,4,5]$. Additionally, physical traits such as light eye color, fair skin color, and poor ability to tan were all found to be increased risk factors for uveal melanoma [6]. The ongoing SEER study has shown a trend from surgical toward radiation therapy as primary treatment $[5,7]$. However, 5 -year survival rates have remained stable around $76-$ $84 \%[2,4,7,8]$.

The association between ocular melanocytosis and uveal melanoma has been well established [9-14]. Ocular melanocytosis is a congenital increased pigmentation of the uveal tract and episclera due to an increased number of melanocytes [15]. This may be associated with a similar increase in melanocytes and pigment in the periocular skin, orbit, meninges, palate, or tympanic membrane termed as oculodermal melanocytosis. Both conditions have been associated with uveal melanoma, and patients with melanocytosis comprise $1.4 \%$ of patients with uveal melanoma [9]. Approximately 1 in 400 Caucasian patients with oculodermal melanocytosis develop uveal melanoma [16]. For Caucasian patients with oculodermal melanocytosis, the prevalence of uveal melanoma is estimated to be $2.6 \times 10^{-3}$ [16]. For patients with sectoral disease, the melanoma arose from the zone of uveal melanocytosis $[9,17]$. This suggests malignant transformation of the melanocytes in melanocytosis. Ocular melanocytosis has also been linked to increased risk of metastasis in patients with melanoma [18].

Classically, ocular melanocytosis has been associated with only uveal melanoma, including choroidal and iris

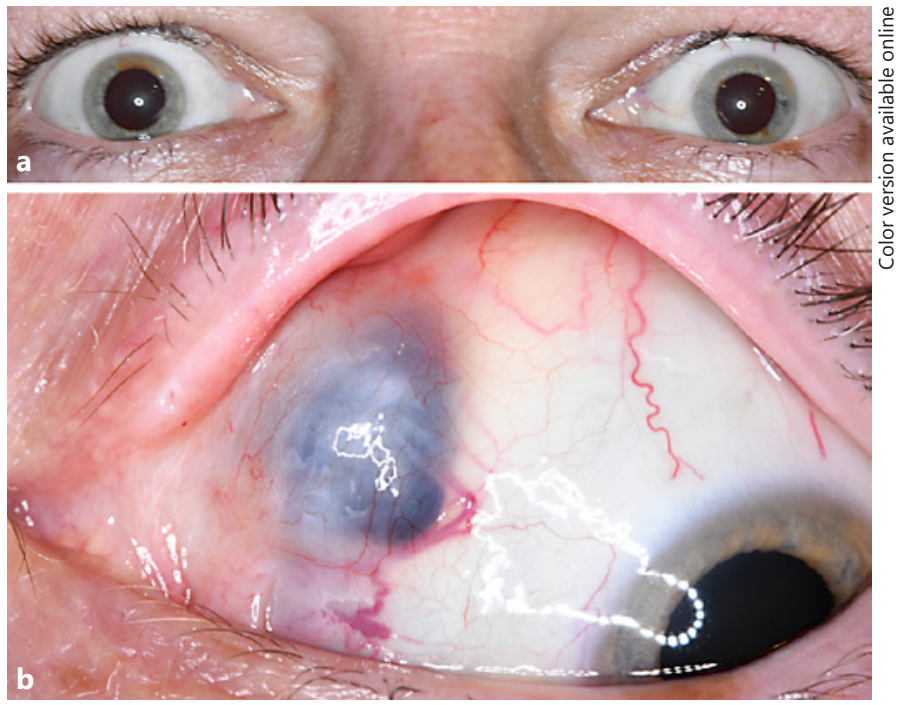

Fig. 1. a Racoon eye photo showing the patient in normal gaze position, note tumor and feeder vessels are not visible in this position. b Superonasal darkly pigmented episcleral mass of the left eye with associated feeder vessels.

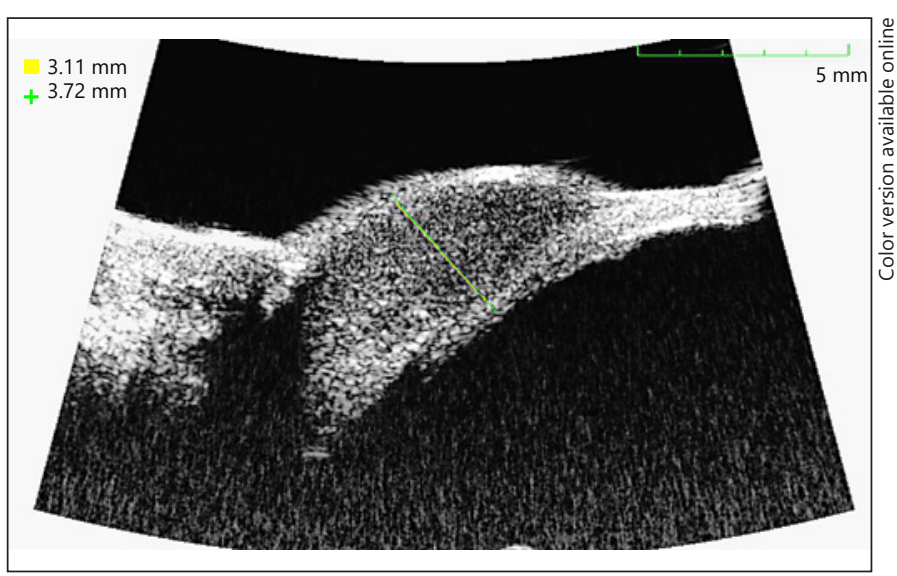

Fig. 2. Ultrasound biomicroscopy showing a mass of the episclera without intraocular extension.

melanoma [9-14, 19-21]. However, 2 cases of melanoma isolated to the episclera associated with ocular melanocytosis have been reported [22, 23]. Here, we present a third case of episcleral melanoma and its surgical excision that appears to have also originated from episcleral ocular melanocytosis. Additionally, it is the first case to have the genetic profile of melanoma determined with a genetic mutation consistent with uveal melanoma. It is also the first case of episcleral melanoma with the surgical margins treated with Gamma Knife stereotactic radiosurgery.
Ocul Oncol Pathol 2020;6:93-98 DOI: $10.1159 / 000502309$
Langevin/Chang/Wang/Deutsch/Otten/ Marr 
Fig. 3. a $\mathrm{T} 1$ postcontrast MRI showing a well-circumscribed mass over the left superonasal globe. b Postcontrast fat saturated axial T1 image showing a well-circumscribed episcleral mass of the left eye.
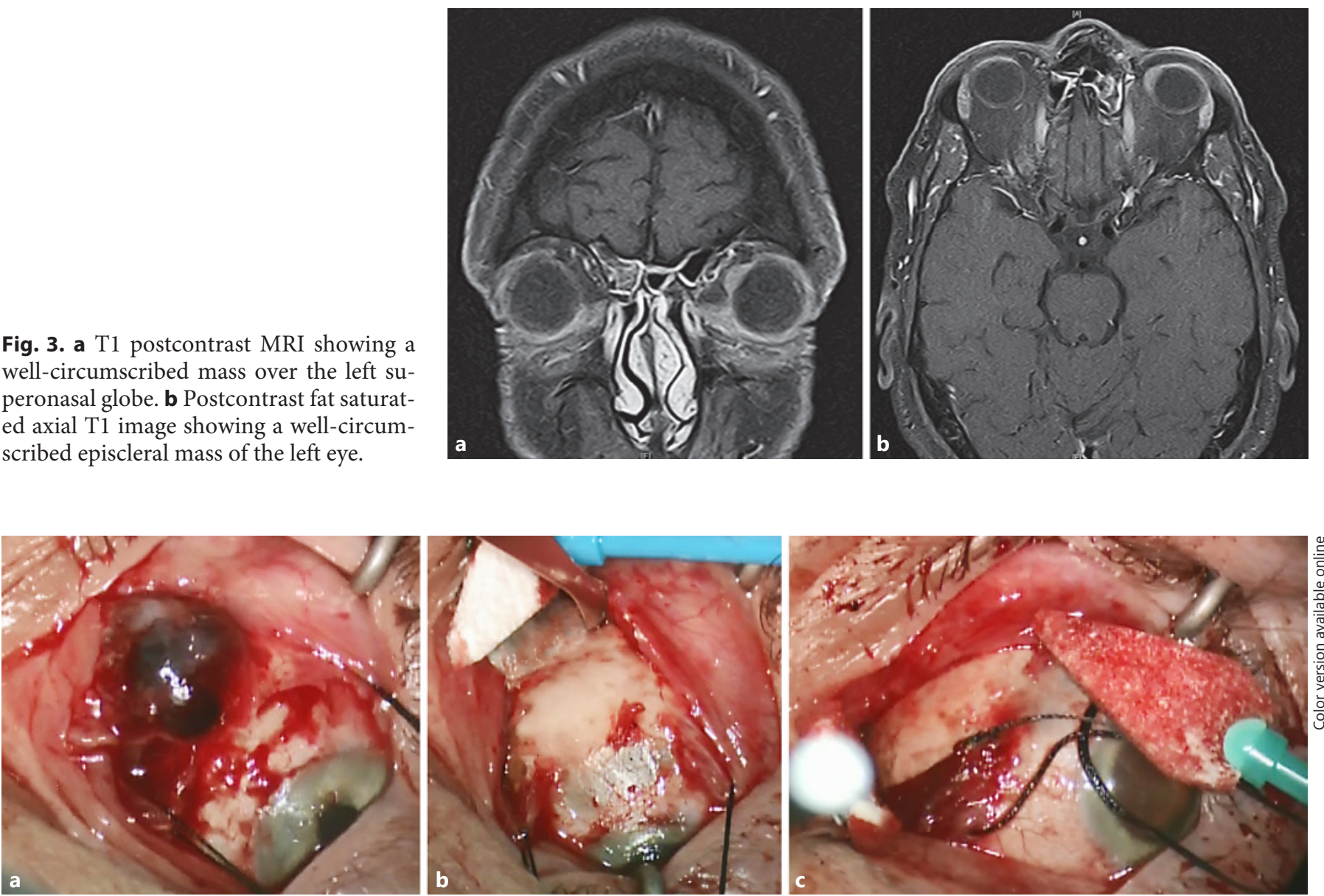

Fig. 4. a Retraction of peritomy revealing a greater extent of the mass than preoperative imaging indicated. b Excision of posterior margin of episcleral mass. c Bare sclera photograph after removal of the mass with no residual tumor present.

\section{Case Report}

A 65-year-old Caucasian male presented with discomfort and tearing of his left eye for approximately 3-4 months. He otherwise denied any change in his overall health and vision. Past medical history was significant for prostate cancer, hypertension, Lyme disease, and Niemann-pick disease. Surgical history included radiation for prostate cancer, and cholecystectomy. Family history of cancer was positive for leukemia in his mother. Visual acuity at presentation by Snellen chart was 20/20 in both eyes. Intraocular pressures were $18 \mathrm{~mm} \mathrm{Hg}$ in both eyes. Eyelid, adnexa, and the lacrimal system were unremarkable in both eyes. Right eye anterior chamber examination was unremarkable as well. Left eye external examination revealed a darkly pigmented mass in the episclera with two large feeder vessels adjacent to it, measuring approximately $8 \times 5 \mathrm{~mm}$ (Fig. 1a, b). Fundus exam of both eyes revealed a clear media, normal optic nerves with a cup-to-disc ratio of 0.3 in each eye. Choroidal melanocytosis was not observed. Ultrasound biomicroscopy was performed, and an episcleral mass with a thickness of $3.1 \mathrm{~mm}$ was noted to be contained within the scleral wall, and no intraocular extension was observed (Fig. 2).
MRI of the orbits was performed with and without contrast and revealed a circumscribed episcleral hyperintense postcontrast lesion without any evidence of orbital extension or disease (Fig. 3a, b).

Treatment options were presented to the patient including the following: excisional or incisional biopsy versus exenteration of orbit or orbital radiation. Excisional biopsy and 180-degree peritomy with isolation of both superior and medial rectus muscles and dissection of tenon's capsule away from the scleral bed were performed (Fig. 4). An episcleral pigmented mass was identified and noted to be more extensive than both ultrasonography and MRI imaging had identified. The flat component extended on the episclera with two elevations that extended posteriorly to near the insertion of the optic nerve. Using a no-touch technique, freeing the tissue overlying and around the pigmented mass, partial lamellar sclerectomy was performed until the entire mass was removed en bloc (Fig. $4 \mathrm{a}-\mathrm{c}$ ). Overlying conjunctiva was noted to be normal during the excision, and the tumor was confined to the episclera. It was also noticed during and prior to the procedure that there was episcleral melanocytosis that could be seen speckled in other places around the sclera and concentrated on the posterior episclera in 


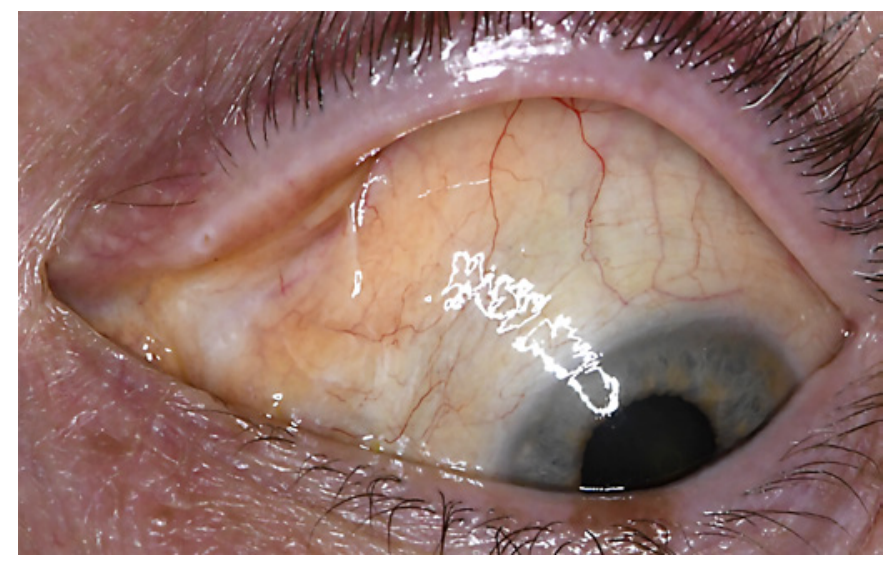

Fig. 5. Postoperative photograph of the left eye 6 months after surgery and radiation with no signs of recurrence or mass.

areas uninvolved with the tumor. This lesion was removed intact. Adjunctive cryotherapy was applied to the surrounding orbital tissues adjacent to the resection site. Then, sterile water was used to irrigate the orbit. The conjunctiva was reflected and peritomy was closed using 7-0 vicryl sutures. The specimen was submitted to anatomic pathology.

Pathology measured the en bloc resected specimen as a $2.0 \times$ $0.9 \times 0.4 \mathrm{~cm}$ specimen. A dense fibrous lesion which was involved by a proliferation of atypical epithelioid and spindle cells arranged in sheets and nodules was reported. Individual tumor cells had an abundant pale eosinophilic to amphophilic cytoplasm. The nuclei were large and ovoid, with vesicular chromatin and prominent single nucleoli. Mitoses were present but uncommon, up to 2 mitoses per millimeter. No perineural or lymphovascular invasion was seen. No necrosis was identified. Pathologic diagnosis was consistent with melanoma; however, surgical margins were microscopically involved at the episcleral base.

Next-generation sequencing was performed at the Columbia University Medical Center (New York, NY, USA) to identify the genetic basis of the melanoma and was positive for a GNA-11 mutation. Negative mutations included BRAF, NRAS, and KIT. The sequencing in this case revealed mutations similar to melanomas of uveal lineage. Gene expression profiling was tested from the original specimen and was Class 2 PRAME positive using commercially available decision $\mathrm{dx}$ Castle bioscience testing.

For definitive globe sparing treatment, adjunctive radiation therapy was recommended as an alternative to orbital exenteration. The patient was referred to the Gamma Knife treatment center for treatment evaluation.

Gamma Knife stereotactic radiosurgery required the eye to be immobilized for treatment planning and treatment delivery. The patient was brought to the Gamma Knife suite, and retrobulbar anesthesia was administered consisting of $5 \mathrm{~mL}$ of a $1: 1$ ratio of $2 \%$ lidocaine and $0.75 \%$ bupivacaine. His eye position was optimized by using 2, 5-0 nylon sutures in which the limbus was sutured to the caruncle. His eye was then lubricated with artificial tears ointment, and the eyelids and globe were covered with transparent adhesive dressing. Then, the stereotactic frame was secured to his skull. Afterwards, the surgical bed and orbit were treated with the Gamma Knife, targeting 20 Gy to the $50 \%$ isodose line. Cone beam
CT scans were performed before and after therapy to confirm that his eye was positioned correctly and did not move for the duration of therapy. All instrumentation and sutures were removed and our patient was sent home the same day.

The patient was seen for follow-up 6 weeks later with a visual acuity of 20/25, normal intraocular pressures, and no signs of residual or recurrent disease on both slit-lamp examination or Bscan ultrasonography (Fig. 5).

\section{Discussion}

Pigmentation of the sclera is noted in several conditions including: Axenfeld nerve loop, episcleral melanocytosis, ochronosis, conjunctival nevus, blue nevus, conjunctival melanoma with deep extension, extraocular extension of uveal melanoma, or metastatic melanoma [22]. A careful examination including detailed ophthalmoscopy, fundoscopy, B-scan ultrasonography, ultrasound biomicroscopy, and optical coherence tomography can be used to elicit the appropriate diagnosis in most cases clinically.

To the best of our knowledge, there have only been two reported cases of isolated episcleral melanoma in the literature $[22,23]$. One case of episcleral melanoma arose from a patient with pre-existing scleral melanosis and the other did not $[22,23]$. Initial examination of our patient showed no ocular pigmentation in the sclera anteriorly or within the uveal tract but was seen during surgical excision on the posterior sclera. The two previous cases of episcleral melanoma were anterior and had a considerably smaller mass measuring $4.0 \times 3.5 \mathrm{~mm}$ and $0.5 \times 0.5$ $\mathrm{mm}$, respectively, compared to our case with a mass measuring $20 \times 9.0 \mathrm{~mm}$. Our case was likely much larger due to its location being covered by the upper eyelid and its location in the orbit, which allowed the mass to reach a greater size before detection.

This case of episcleral melanoma is the first in which genetic testing was available to demonstrate the genetic similarities to uveal melanoma rather than conjunctival melanoma. The prior two cases were treated as a conjunctival melanoma and were resected en bloc with freezethaw cryotherapy, which we performed during our surgical excision as well.

After excision, radiation treatment of presumed microscopic residual tissue within the surgical bed and surrounding orbital tissue was prudent, since direct visualization for posterior recurrence would not be optimal. We considered plaque brachytherapy, proton beam radiosurgery, and Gamma Knife stereotactic radiotherapy. Plaque brachytherapy would have radiated in the direc- 
tion of the eye and would not have treated the potential direct extension into the orbit unless unshielded, and all proton beam radiosurgery centers required travel that was not feasible for the patient.

Gamma Knife stereotactic radiosurgery is becoming an alternative option for treating ocular melanoma when plaque brachytherapy is not indicated. Recent publications have shown that Gamma Knife stereotactic radiosurgery is effective in the treatment of uveal melanoma, with most authors treating $20-25$ Gy to the $50 \%$ isodose margin with similar outcomes for survival compared to enucleation and plaque brachytherapy [24-26]. Unfortunately, these cases also come with a risk of radiation side effects which are higher than with brachytherapy alone [27]. As this tumor was genetically similar to uveal melanoma, we followed the guidelines from previously published literature on treating primary uveal melanoma with Gamma Knife and applying the same technique to the surgical bed. Figure 4 shows the extent of surgical bed and surrounding structures.

Due to the rarity of this condition, there is no available data concerning prognosis and appropriate surveillance of our patient besides the gene expression profiling (GEP) for intraocular disease which may or may not apply. The patient remains free of recurrence at 6 months and close local and systemic surveillance with imaging continues.

\section{Statement of Ethics}

This research was conducted in accordance with the World Medical Association Declaration of Helsinki. Written consent was obtained from our patient to publish this material. Institutional Review Board committee approval was not needed as this is a single retrospective case report with de-identified data, and permission from the patient was directly obtained to report his case.

\section{Disclosure Statement}

Dr. Wang reports personal fees and non-financial support from AbbVie, non-financial support from Merck, personal fees from AstraZeneca, personal fees from Doximity, personal fees and non-financial support from Novocure, personal fees and non-financial support from Elekta, and personal fees from Wolters Kluwer, outside the submitted work. Dr. Marr is a consultant for Aura Biosciences, Castle Biosciences, and Immunocore.

\section{References}

1 Chang AE, Karnell LH, Menck HR; The American College of Surgeons Commission on Cancer and the American Cancer Society. The National Cancer Data Base report on cutaneous and noncutaneous melanoma: a summary of 84,836 cases from the past decade. Cancer. 1998 Oct;83(8):1664-78.

2 Singh AD, Turell ME, Topham AK. Uveal melanoma: trends in incidence, treatment, and survival. Ophthalmology. 2011 Sep; 118(9):1881-5.

3 Shields CL, Furuta M, Thangappan A, Nagori S, Mashayekhi A, Lally DR, et al. Metastasis of uveal melanoma millimeter-by-millimeter in 8033 consecutive eyes. Arch Ophthalmol. 2009 Aug;127(8):989-98

4 Shields CL, Kaliki S, Cohen MN, Shields PW, Furuta M, Shields JA. Prognosis of uveal melanoma based on race in 8100 patients: The 2015 Doyne Lecture. Eye (Lond). 2015 Aug; 29(8):1027-35.

5 Mahendraraj K, Lau CS, Lee I, Chamberlain RS. Trends in incidence, survival, and management of uveal melanoma: a populationbased study of 7,516 patients from the Surveillance, Epidemiology, and End Results database (1973-2012). Clin Ophthalmol. 2016 Oct; $10: 2113-9$.

6 Weis E, Shah CP, Lajous M, Shields JA, Shields CL. The association between host susceptibility factors and uveal melanoma: a meta-analysis. Arch Ophthalmol. 2006 Jan;124(1):54-60.
7 Aronow ME, Topham AK, Singh AD. Uveal melanoma: 5-year update on incidence, treatment, and survival (SEER 1973-2013). Ocul Oncol Pathol. 2018 Apr;4(3):145-51.

8 Singh AD, Topham A. Survival rates with uveal melanoma in the United States: 19731997. Ophthalmology. 2003 May;110(5):9625.

9 Gonder JR, Shields JA, Albert DM, Augsburger JJ, Lavin PT. Uveal malignant melanoma associated with ocular and oculodermal melanocytosis. Ophthalmology. 1982 Aug;89(8): 953-60.

10 Velazquez N, Jones IS. Ocular and oculodermal melanocytosis associated with uveal melanoma. Ophthalmology. 1983 Dec;90(12): $1472-6$.

11 Pomeranz GA, Bunt AH, Kalina RE. Multifocal choroidal melanoma in ocular melanocytosis. Arch Ophthalmol. 1981 May;99(5): 857-63.

12 Gonder JR, Shields JA, Shakin JL, Albert DM. Bilateral ocular melanocytosis with malignant melanoma of the choroid. Br J Ophthalmol. 1981 Dec;65(12):843-5.

13 Honavar SG, Shields CL, Singh AD, Demirci $\mathrm{H}$, Rutledge BK, Shields JA, et al. Two discrete choroidal melanomas in an eye with ocular melanocytosis. Surv Ophthalmol. 2002 JanFeb;47(1):36-41.
14 Shields CL, Eagle RC, Ip MS, Marr BP, Shields JA. Two discrete uveal melanomas in a child with ocular melanocytosis. Retina. 2006 JulAug;26(6):684-7.

15 Fitzpatrick TB, Kitamura H, Kukita A, Zeller R. Ocular and dermal melanocytosis. AMA Arch Opthalmol. 1956 Dec;56(6):830-2.

16 Singh AD, De Potter P, Fijal BA, Shields CL, Shields JA, Elston RC. Lifetime prevalence of uveal melanoma in white patients with oculo(dermal) melanocytosis. Ophthalmology. 1998 Jan;105(1):195-8.

17 Shields CL, Qureshi A, Mashayekhi A, Park C, Sinha N, Zolotarev F, et al. Sector (partial) oculo(dermal) melanocytosis in 89 eyes. Ophthalmology. 2011 Dec;118(12):2474-9.

18 Shields CL, Kaliki S, Livesey M, Walker B, Garoon R, Bucci M, et al. Association of ocular and oculodermal melanocytosis with the rate of uveal melanoma metastasis: analysis of 7872 consecutive eyes. JAMA Ophthalmol. 2013 Aug;131(8):993-1003.

19 Shields JA, Shields CL, Davidson R, Eagle RC Jr. Iris melanoma arising from sector congenital ocular melanocytosis in a child. Cornea. 2009 Dec;28(10):1191-3.

20 Qian Y, Zakov ZN, Schoenfield L, Singh AD. Iris melanoma arising in iris nevus in oculo(dermal) melanocytosis. Surv Ophthalmol. 2008 Jul-Aug;53(4):411-5. 
$21 \mathrm{Cu}-$ Unjieng AB, Shields CL, Shields JA, Eagle RC Jr. Iris melanoma in ocular melanocytosis. Cornea. 1995 Mar;14(2):206-9.

22 Gündüz K, Shields JA, Shields CL, Eagle RC Jr. Episcleral melanoma without conjunctival or uveal involvement. Br J Ophthalmol. 1998 Nov;82(11):1342-3.

23 Louwagie CR, Baratz KH, Pulido JS, Salomão DR, Dierks DL. Episcleral melanoma as a complication of ocular melanocytosis. Graefes Arch Clin Exp Ophthalmol. 2008 Sep; 246(9):1351-3.
24 Arnett AL, Reynolds MM, Pulido JS, Parney IF, Laack NN. Gamma Knife Stereotactic Radiosurgery for the Treatment of Primary and Metastatic Ocular Malignancies. Stereotact Funct Neurosurg. 2017;95(6):363-8.

25 Fakiris AJ, Lo SS, Henderson MA, Witt TC, Worth RM, Danis RP, Des Rosiers PM, Timmerman RD. Gamma-Knife-based sterotactic radiosurgery for uveal melanoma. Stereotact Funct Neurosurg. 2007;85(2-3):106-12.
26 Schirmer CM, Chan M, Mignano J, Duker J, Melhus CS, Williams LB, et al. Dose de-escalation with gamma knife radiosurgery in the treatment of choroidal melanoma. Int J Radiat Oncol Biol Phys. 2009 Sep;75(1):170-6.

27 Krema H, Heydarian M, Beiki-Ardakani A, Weisbrod D, Xu W, Simpson ER, et al. A comparison between 125 Iodine brachytherapy and stereotactic radiotherapy in the management of juxtapapillary choroidal melanoma. Br J Ophthalmol. 2013 Mar;97(3):327-32. 